\title{
Applications and toxicity of graphene family nanomaterials and their composites
}

This article was published in the following Dove Press journal:

Nanotechnology, Science and Applications

16 March 2016

Number of times this article has been viewed

\section{Zorawar Singh \\ Department of Zoology, Khalsa College, Amritsar, Punjab, India}

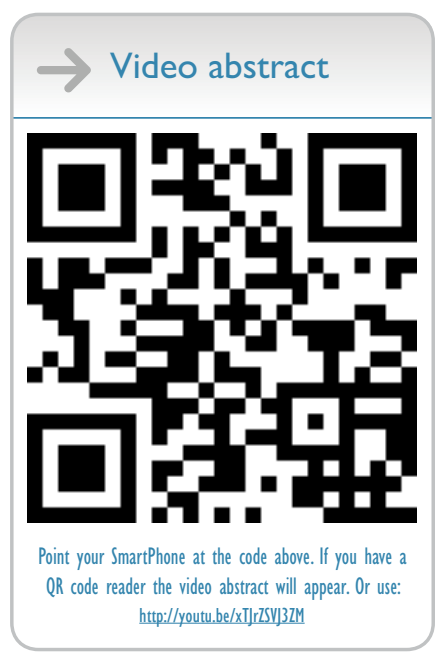

Correspondence: Zorawar Singh Department of Zoology, Khalsa College, G.T. Road, Amritsar I43005, Punjab, India Tel +9l 94 I7230075 Email zorawarsinghs@rediffmail.com

\begin{abstract}
Graphene has attracted much attention of scientific community due to its enormous potential in different fields, including medical sciences, agriculture, food safety, cancer research, and tissue engineering. The potential for widespread human exposure raises safety concerns about graphene and its derivatives, referred to as graphene family nanomaterials (GFNs). Due to their unique chemical and physical properties, graphene and its derivatives have found important places in their respective application fields, yet they are being found to have cytotoxic and genotoxic effects too. Since the discovery of graphene, a number of researches are being conducted to find out the toxic potential of GFNs to different cell and animal models, finding their suitability for being used in new and varied innovative fields. This paper presents a systematic review of the research done on GFNs and gives an insight into the mode and action of these nanosized moieties. The paper also emphasizes on the recent and up-to-date developments in research on GFNs and their nanocomposites for their toxic effects.
\end{abstract}

Keywords: graphene, quantum dots, desalination, drug delivery, antibacterial, cytotoxicity, genotoxicity

\section{Introduction}

Graphene has emerged as a sensational nanocarbon with unusual properties. Graphene is a two-dimensional planar and hexagonal array of carbon atoms. Each of these carbons is $\mathrm{sp}^{2}$-hybridized and has four bonds, one $\sigma$ bond with each of its three neighbors and one $\pi$-bond that is oriented out of plane. It is a gapless material with ballistic conduction at room temperature and high carrier mobility. The complete planar exposure of the carbon atoms renders graphene a theoretical surface area $>2,500 \mathrm{~m}^{2} / \mathrm{g}$. The new properties of graphene and its hybrid structures have been widely explored for advanced technological applications in electronics, optics, and various other fields. Graphene has attracted attention among the scientific community since it was developed as a single layer of material by Novoselov et $\mathrm{al}^{1}$ by using the scotch tape method. It consists of carbon atoms arranged in a honeycomb lattice and has a thickness of a single atom. It has the property of extremely high intrinsic mobility of charge carriers. It has a zero band gap and high chemical stability. Related materials include few-layer graphene, ultrathin graphite, graphene oxide (GO), reduced graphene oxide (rGO), and graphene nanosheets. Graphene materials vary in layer number, lateral dimension, surface chemistry, defect density, or quality of the individual graphene sheets, and composition or purity. In this way, GFNs are analogous to carbon nanotubes (CNTs), which vary in wall number, diameter, length, surface chemistry and the amount, composition, and 
physical form of metal impurities. ${ }^{2}$ Graphene quantum dots (GQDs) constitute a zero-dimensional photoluminescence carbon-based nanomaterial consisting of very thin graphene sheets (3-20 nm). The band gap in GQDs is nonzero and can be set by altering the size and the surface chemistry of the dots. ${ }^{3}$ Graphene and its derivatives, referred to as graphene family nanomaterials (GFNs) have been evaluated for their applications and toxicity.

\section{Recent developments in applications of GFNs}

In recent years, various novel nanomaterials have received much attention due to their great potential for applications in agriculture, ${ }^{4-7}$ food safety, and food packaging. ${ }^{8-16}$ Among them, GFNs are emerging as promising nanomaterials that will have a major role to play in different application fields of medical and physical sciences.

\section{Electronics}

GFNs have been extensively used in the field of electronics. ${ }^{17-22}$ Graphene has been used for broadband and ultrafast photodetection and optical modulation. These optoelectronic capabilities can augment complementary metal oxide semiconductor (CMOS) devices for high-speed and low-power optical interconnects. ${ }^{23}$ Recent studies have shown that GFNs have been used for their applications in organic electronics, ${ }^{19}$ making ultra high-rate supercapacitors for wearable electronics, ${ }^{20}$ metal-graphene contacts, ${ }^{21}$ integrated circuits and multifunctional electronics, ${ }^{22} \mathrm{CNT}$ network for monolithic all-carbon electronics, ${ }^{24}$ low-voltage organic electronics, ${ }^{25}$ and flexible electronics. ${ }^{17,22,26-31}$ Graphene also has attracted much interest in radio frequency electronics because of its superior electrical properties. ${ }^{32}$ Graphene circuits exhibited outstanding thermal stability with little reduction in performance when integrated circuits operates as a broadband radio frequency mixer at frequencies up to $10 \mathrm{GHz} \cdot{ }^{33}$ Composite multiwalled CNTs-GO electrochemical capacitor electrodes with superior performance to solely GO electrodes were reported. The measured capacitance improved threefold and reached a maximum specific capacitance of $231 \mathrm{~F} / \mathrm{g} .{ }^{34}$

\section{Desalination}

Graphene, with its microporous structure, has become a center of attraction in the field of water filtration and desalination..$^{35-41}$ Graphene was found to effectively filter $\mathrm{NaCl}$ salt from water. ${ }^{41}$ Nanoporous graphene (NPG) shows tremendous promise as an ultrapermeable membrane for water desalination, which is due to its atomic thickness and precise sieving properties. ${ }^{37}$
Graphene can be modified by creating nanopores on the surface $^{35}$ and well-structured channels of pores facilitate the flow of water making the flow fast as compared with reverse osmosis (RO) membranes. By modifying the size of the pores, specific materials other than salt, based on their molecular size, can also be filtered out. There is less understanding as to whether NPG is strong enough to maintain its mechanical integrity under the high hydraulic pressures inherent to the RO desalination process. ${ }^{36}$ An NPG membrane can maintain its mechanical integrity in RO, but the choice of substrate for graphene is critical to this performance. Nicolai et a ${ }^{38}$ assessed GO framework membranes for water desalination using classical molecular dynamics simulations. For a given pore size ( $\mathrm{n}=16$ or 32 ), water permeability of GO framework membranes increases when the pore spacing decreases, whereas for a given pore spacing $(\mathrm{n}=32$ or 64$)$, water permeability increases by up to 2 orders of magnitude when the pore size increases. Carboxyl functional groups can enhance ion exclusion for all pores considered, but the effect becomes less pronounced as both the ion concentration and the pore diameter increase. ${ }^{39}$ When compared with a CNT of similar pore diameter, graphene sheet pores functionalized with $\mathrm{COO}^{-}$groups were found to be more effective in excluding $\mathrm{Cl}^{-}$ions from passing through the membrane.

\section{Tissue engineering}

Graphene has been found useful in the field of bone tissue applications. ${ }^{42-46} \mathrm{GO}$ has a beneficial effect on cell proliferation and differentiation, thus holding promise for bone tissue engineering approaches. ${ }^{47} \mathrm{~A}$ study proposed the combination of a three-dimensional (3D) graphene foam scaffold loaded with bone marrow-derived mesenchymal stem cells to improve skin wound healing. ${ }^{48}$ The development of materials and strategies that can influence stem cell attachment, proliferation, and differentiation toward osteoblasts is of high interest to promote faster healing and reconstructions of large bone defects. Graphene finds its biomedical applications as they present remarkable properties such as high surface area, high mechanical strength, and ease of functionalization. ${ }^{49}$ Graphene was tested as a biocompatible inert nanomaterial, for its effect on in vitro growth and differentiation of goat adult mesenchymal stem cells. Cell proliferation and differentiation were compared between polystyrene-coated tissue culture plates and graphene-coated plates. Graphitic materials were found to be cytocompatible, which supported cell adhesion and proliferation. ${ }^{50}$ Soft graphene nanofibers designed for the acceleration of nerve growth and development are also reported. ${ }^{51}$ New and recent developments are being done 
by various researchers by taking GFNs in the field of tissue engineering, like Lopez-Dolado et $\mathrm{al}^{52}$ investigated neural regeneration with subacute responses of the rat with injured spinal cord to three-dimensional graphene oxide (3DGO) scaffolds; Zhang et $\mathrm{a}^{53}$ incorporated GO into poly(lactic acid) (PLA) as a reinforcing nanofiller to produce composite nanofibrous scaffolds using the electrospinning technique for potential tissue engineering applications; Liao et $\mathrm{al}^{54}$ prepared a hybrid scaffold composed of methacrylated chondroitin sulfate, poly(ethylene glycol) methyl ether- $\varepsilon$-caprolactoneacryloyl chloride, and GO revealing that methacrylated chondroitin sulfate/poly(ethylenetglycol) methyl ether- $\varepsilon$ caprolactone-acryloyl chloride/GO hybrid porous scaffold can be applied in articular cartilage tissue engineering. Osteoblast proliferation and differentiation was found to be significantly higher in the poly( $\varepsilon$-caprolactone) (PCL) scaffolds containing the strontium-decorated $\mathrm{rGO}$ particles in contrast to neat PCL and PCL/rGO scaffolds. ${ }^{55}$

\section{Cancer treatments}

Graphene and its nanocomposites have gained much attention in recent times in cancer therapy as nanotheranostics. They have a low production cost, ease in synthesis, and different physicochemical properties including ultralarge surface area with planar structure and p-p conjugation with the unsaturated and aromatic biomolecules that are favorable for drug targeting. ${ }^{56}$ Limited studies are available on the use of graphene family nanoparticles in cancer therapy, yet they point out a new possibility of using these key compounds in this field. Different recent studies have revealed the potential of graphene family nanoparticles in the detection of different cancer types. ${ }^{57-62}$ Rhodamine-functionalized GQDs have been used for detection of $\mathrm{Fe}^{3+}$ in cancer stem cells. ${ }^{63}$ A label-free, suspended single crystalline graphene sensor has been used for multiplex lung cancer tumor marker detection. ${ }^{64}$ Peroxidase-active nanohybrid of gold nanoparticle-loaded mesoporous silica-coated graphene has also been used for cancer cell detection. ${ }^{65}$ Yim et al ${ }^{66}$ used GO-encoded silver nanoshells with single-particle detection sensitivity toward cancer cell imaging. The ultrasensitive nanoprobe successfully demonstrated its potential for bioimaging of cancer cells using Raman spectroscopy. Circulating tumor cells are a group of rare cancer cells that have detached from a primary tumor and circulate in the bloodstream. Circulating tumor cells were detected in prostate cancer based on carboxylated GO-modified light addressable potentiometric sensor. ${ }^{59}$
Cancer biomarker is a substance that is indicative of the presence of cancer in the body. A biomarker may be a molecule secreted by a tumor or a specific response of the body to the presence of cancer. Detection of cancer biomarkers has always been the field of concern for researchers. GFNs have been extensively exploited for the detection of various cancer biomarkers. ${ }^{62,67-72}$ Ovarian cancer biomarker (CA-125) was detected using chemiluminescence resonance energy transfer to GQDs. ${ }^{62}$ Similarly, electrochemical immunosensor with $\mathrm{N}$-doped graphene-modified electrode was used for label-free detection of the breast cancer biomarker (CA 15-3). ${ }^{71}$ A paperbased microfluidic electrochemical immuno-device integrated with nanobioprobes onto graphene film was used for ultrasensitive multiplexed detection of cancer biomarkers. ${ }^{72}$ Highly sensitive luminol electrochemiluminescence immunosensor based on zinc oxide nanoparticles and glucose oxidase decorated graphene has been used for cancer biomarker detection. ${ }^{73}$ Similarly, different other methods have been proposed for the detection of cancer biomarkers including magnetic graphene nanosheets-based electrochemiluminescence immunoassay using cadmium telluride QD-coated silica nanospheres as labels ${ }^{74}$; graphene-encapsulated nanoparticle-based biosensor ${ }^{75}$; cathodic electro-generated chemiluminescence immunosensor based on luminol and graphene $^{76}$; and sensitive immunosensor based on dual signal amplification strategy of graphene sheets and multienzyme functionalized carbon nanospheres. ${ }^{77}$ Graphene was found useful in delivering gambogic acid (GA) to breast and pancreatic cancer cells in vitro with no shown toxicity. Antiproliferative effects of GA were found to be significantly enhanced by its nanodelivery. ${ }^{78}$

\section{Metal detection and removal}

Graphene has been found to have high metal adsorption tendencies. ${ }^{79-81}$ Nafion-graphene nanocomposite solution in combination with an in situ plated mercury film electrode was used as a highly sensitive electrochemical platform for the determination of $\mathrm{Zn}$ (II), $\mathrm{Cd}(\mathrm{II}), \mathrm{Pb}(\mathrm{II})$, and $\mathrm{Cu}$ (II) in $0.1 \mathrm{M}$ acetate buffer ( $\mathrm{pH} 4.6$ ) by square-wave anodic stripping voltammetry. ${ }^{82}$ Viraka Nellore et $\mathrm{al}^{83}$ reported the development of PGLa antimicrobial peptide and glutathioneconjugated CNT-bridged 3DGO membrane, which can be used for removal of $\mathrm{As}(\mathrm{III}), \mathrm{As}(\mathrm{V})$, and $\mathrm{Pb}(\mathrm{II})$ from water. GO sheets were used in aqueous samples for a fast and efficient adsorption of $\mathrm{Pb}(\mathrm{II}), \mathrm{Cd}(\mathrm{II}), \mathrm{Bi}(\mathrm{III})$, and $\mathrm{Sb}$ (III) owing to its hydrophilic character and the electrostatic repulsion among the GO sheets. ${ }^{84}$ The effectiveness of GO/ carboxymethyl cellulose (GO/CMC) monoliths was tested for 
their adsorbing capabilities. The porous $\mathrm{GO} / \mathrm{CMC}$ monoliths were found to exhibit a strong ability to adsorb metal ions. As CMC is biodegradable and nontoxic, the porous $\mathrm{GO} / \mathrm{CMC}$ monoliths were found to be potential environmental adsorbents. ${ }^{79}$ An et al ${ }^{85}$ described the fabrication and characterization of ionic liquid-gated field-effect transistor (FET)-type flexible graphene aptasensor with high sensitivity and selectivity for mercury in mussels. This aptasensor has potential for detecting $\mathrm{Hg}$ exposure in human and in the environment. Henriques et $\mathrm{al}^{86}$ explored the preparation of 3DGO macroscopic structures, shaped by self-assembling single GO sheets with control of its surface chemistry by combining with nitrogen functional groups or with nitrogen and sulfur functional groups and their application in the removal of $\mathrm{Hg}$ (II) from aqueous solutions.

\section{Drug delivery systems}

Local delivery of drug molecules to target tissues provides a means for effective drug dosing, while reducing the adverse effects of systemic drug delivery. ${ }^{87}$ Chowdhury et al ${ }^{88}$ reported the use of poly(ethylene glycol)-distearoylphosph atidylethanolamine-coated oxidized graphene nanoribbons as agent for delivery of antitumor drug lucanthone into glioblastoma multiforme cells targeting base excision repair enzyme apurinic endonuclease- 1 . Weaver et al ${ }^{87}$ explored an electrically controlled drug delivery nanocomposite composed of GO deposited inside a conducting polymer scaffold. The nanocomposite was loaded with dexamethasone and exhibited favorable electrical properties. In response to voltage stimulation, the nanocomposite releases drug with a linear release profile and a dosage that can be adjusted by altering the magnitude of stimulation. No toxic byproducts were found to leach from the film during electrical stimulation. Antiproliferative effects of GA on breast and pancreatic cancer cells were found to be significantly enhanced by its nanodelivery using graphene with no shown toxicity. ${ }^{78}$ Many recent studies have also used graphene or its composites for delivering or monitoring the delivery systems of various compounds. ${ }^{89-94}$ Angelopoulou et $\mathrm{a}^{89}$ investigated the application of water-dispersible poly(lactide)-poly(ethylene glycol) (PLA-PEG) copolymers for the stabilization of GO aqueous dispersions and using the PLA-PEG-stabilized GO as a delivery system for the potent anticancer agent paclitaxel. PLA-PEG was found to stabilize GO for the controlled delivery of paclitaxel into A549 cancer cells. GFNs and their nanocomposites as starch functionalized graphene, ${ }^{95} \mathrm{Pt}(\mathrm{IV})$ conjugated nano-GO, ${ }^{96}$ PEGylated GO, ${ }^{97-100} \mathrm{GO}$ stabilized in electrolyte solutions using hydroxyethyl cellulose, ${ }^{101}$
DNA-graphene hybrid nanoaggregates, ${ }^{102}$ and GO-wrapped mesoporous silica nanoparticles ${ }^{103}$ were used for various drug delivery systems. Table 1 shows the systematic compilation of the studies involving graphene and its composites in drug delivery systems. Chen et $\mathrm{al}^{90}$ demonstrated a GQD-based fluorescence resonance energy transfer system for nucleartargeted drug delivery that allows a real-time monitoring of the drug release. A multifunctional nanocomposite of PLA-PEG-grafted GQDs was also proposed for simultaneous intracellular microRNAs imaging analysis and combined gene delivery for enhanced therapeutic efficiency. ${ }^{91} \mathrm{~A}$ chemically tuned GO for its oxidation state was used to construct a GO-based nanoplatform combined with a $\mathrm{pH}$-sensitive fluorescence tracer designed for both $\mathrm{pH}$ sensing and pH-responsive drug delivery. ${ }^{92}$

\section{Nuclear waste treatment}

There is a vast application potential of GO-based materials in nuclear waste processing. Wu et $\mathrm{al}^{116}$ investigated the interaction mechanisms between actinide cations such as $\mathrm{Np}(\mathrm{V})$ and $\mathrm{Pu}(\mathrm{IV}, \mathrm{VI})$ ions and four types of GOs modified by hydroxyl, carboxyl, and carbonyl groups at the edge and epoxy group on the surface. The binding energies in aqueous solution revealed that the adsorption abilities of all GOs for actinide ions follow the order of $\mathrm{Pu}(\mathrm{IV})>\mathrm{Pu}(\mathrm{VI})>\mathrm{Np}(\mathrm{V})$ and this finding is expected to provide useful information for developing more efficient GO-based materials for radioactive wastewater treatment. Polyacrylamide-grafted GO was applied as an adsorbent for the removal of radionuclides from radioactive wastewater. Maximum sorption capacities of U(VI), Eu(III), and $\mathrm{Co}(\mathrm{II})$ on polyacrylamide-grafted GO were found to be $0.698,1.245$, and $1.621 \mathrm{mmol} / \mathrm{g}$, respectively at $\mathrm{pH} 5.0 \pm 0.1$ and $\mathrm{T}=295 \mathrm{~K}$, which were much higher than those of radionuclides on nascent $\mathrm{GO} .{ }^{117} \mathrm{Wu}$ et $\mathrm{al}^{118}$ also studied the bonding nature of uranyl ion and GO for effective removal of uranium from radioactive wastewater using GO-based materials. Romanchuk et al ${ }^{119}$ studied the interaction of GO with actinides, including Am(III), Th(IV), $\mathrm{Pu}(\mathrm{IV}), \mathrm{Np}(\mathrm{V}), \mathrm{U}(\mathrm{VI})$, and typical fission products $\mathrm{Sr}(\mathrm{II})$, $\mathrm{Eu}(\mathrm{III})$, and Tc(VII). Cation/GO coagulation was expected to facilitate their removal.

\section{Toxicity of graphene family nanoparticles}

The dose, shape, surface chemistry, exposure route, and purity play important roles in differential toxicity of GFNs. ${ }^{120}$ Different authors have used various toxicity tests to evaluate the toxicity of GFNs. ${ }^{121-124}$ Studies have been conducted to 
Table I Studies using GFNs or composites with respect to drug delivery systems

\begin{tabular}{|c|c|c|c|}
\hline Sr no & Authors & GFN or composite used & Purpose of use \\
\hline $\mathrm{I}$. & Li et $\mathrm{al}^{96}$ & $\mathrm{Pt}(\mathrm{IV})$ conjugated nano-GO & To enhance the therapeutic efficacy of Pt drug \\
\hline 2. & Wang et $\mathrm{al}^{104}$ & GQDs & Simultaneous targeted cellular imaging and drug delivery \\
\hline 3. & Wang et al ${ }^{105}$ & Chlorotoxin-conjugated GO & Targeted delivery of an anticancer drug doxorubicin \\
\hline 4. & Wang et al $^{106}$ & Reduced GO-supported gold nanostars & $\begin{array}{l}\text { Improved surface-enhanced Raman scattering sensing } \\
\text { and drug delivery }\end{array}$ \\
\hline 5. & Wang et al ${ }^{107}$ & Cyclic RGD-modified chitosan/GO polymers & Drug delivery and cellular imaging \\
\hline 6. & Song et al ${ }^{108}$ & Hyaluronic acid-decorated GO nanohybrids & Targeted and $\mathrm{pH}$-responsive anticancer drug delivery \\
\hline 7. & Ou et al ${ }^{109}$ & $\begin{array}{l}\mathrm{Fe}_{3} \mathrm{O}_{4} / \mathrm{SiO}_{2} / \text { graphene-CdTe QDs/chitosan } \\
\text { nanocomposites }\end{array}$ & Targeted drug delivery \\
\hline 8. & Liu et al ${ }^{110}$ & $\begin{array}{l}\text { Polyamidoamine dendrimer and oleic acid- } \\
\text { functionalized graphene }\end{array}$ & Biocompatible and efficient gene delivery vectors \\
\hline 9. & Kim and Kim ${ }^{\prime \prime \prime}$ & rGO-polyethylenimine nanocomposite & Photothermally controlled gene delivery \\
\hline 10. & You et al $\left.\right|^{112}$ & Nano-GO & Cancer imaging and drug delivery \\
\hline II. & Rahmanian et al $\left.\right|^{113}$ & Nano-GO & Oral delivery of flavonoids \\
\hline 12. & Liu et $\mathrm{a}^{95}$ & Starch-functionalized graphene & $\mathrm{pH}$-sensitive and starch-mediated drug delivery \\
\hline 13. & Yang et al ${ }^{114}$ & $\mathrm{GO} /$ manganese ferrite nanohybrids & $\begin{array}{l}\text { Magnetic resonance imaging, photothermal therapy, and } \\
\text { drug delivery }\end{array}$ \\
\hline 14. & Wu et $\mathrm{al}^{115}$ & Peptide-GO hybrid hydrogel & Drug delivery and pulsatile triggered release in vivo \\
\hline 15. & Tang et al ${ }^{103}$ & GO-wrapped mesoporous silica nanoparticles & $\begin{array}{l}\text { An aptamer-targeting photoresponsive drug delivery } \\
\text { system }\end{array}$ \\
\hline 16. & Mo et al ${ }^{102}$ & DNA-graphene hybrid nanoaggregates & Anticancer drug delivery doxorubicin \\
\hline 17. & Chen et al $\left.\right|^{100}$ & PEGylated GO & Photothermally controlled drug delivery \\
\hline 18. & Song et $\mathrm{a}^{97}$ & PEGylated GO & Sequential delivery of lidocaine and thalidomide drugs \\
\hline 19. & Xu et a ${ }^{99}$ & PEGylated GO & Delivery of paclitaxel \\
\hline 20. & Mianehrow et al ${ }^{101}$ & $\begin{array}{l}\text { GO stabilized in electrolyte solutions using } \\
\text { hydroxyethyl cellulose }\end{array}$ & Drug delivery \\
\hline
\end{tabular}

Abbreviations: CdTe, cadmium telluride; GFNs, graphene family nanomaterials; GO, graphene oxide; QD, quantum dot; GQDs, graphene quantum dots; rGO, reduced graphene oxide; Sr no, serial number.

find out the toxicity of GFNs on different cellular and animal models, including stem cells, ${ }^{121,125-127} \mathrm{HeLa}$ cells, ${ }^{128,129} \mathrm{HepG} 2$ cells, ${ }^{130,131}$ bacteria, ${ }^{132,133}$ Drosophila melanogaster, ${ }^{134,135}$ Zebrafish, ${ }^{122,136}$ marine organisms, ${ }^{137}$ rats,,${ }^{138}$ mice,,${ }^{123,128,139}$ and mammalian cells. ${ }^{140}$ Cytotoxicity tests indicated that the rGO can damage cells with direct contact. ${ }^{141}$ In this part of the paper, an attempt has been made to compile the recent and up-to-date studies related to toxicological aspects of GFNs to different models.

\section{Toxicity toward bacteria}

Graphene, its derivatives, and composites have been widely reported to possess antibacterial properties. ${ }^{142}$ Different studies involved graphene in bacterial detection methods. ${ }^{143-146} \mathrm{rGO}$ has been used for the detection of bacteria. ${ }^{147}$ Bioactivity of Escherichia coli and their interaction with the environment was controlled by their capture within aggregated graphene nanosheets. Aggregation of the sheets in the melatonin-bacterial suspension was found to trap the bacteria within the aggregated sheets. This trapping results in isolation of the bacteria from their environment, leading to bacterial inactivation. ${ }^{148}$ Bacterial toxicity of graphene nanosheets in the form of graphene nanowalls deposited on stainless steel substrates was investigated for both Gram-positive and Gram-negative models of bacteria. By measuring the efflux of cytoplasmic materials of the bacteria, it was found that the cell membrane damage of the bacteria was due to direct contact of the bacteria with the extremely sharp edges of the nanowalls. It proved to be an effective mechanism in bacterial inactivation. ${ }^{132}$ Gram-negative $E$. coli with an outer membrane were found to be more resistant to this cell membrane damage than the Gram-positive Staphylococcus aureus, which lack the outer membrane. Polyvinyl- $N$-carbazole-GO (PVK-GO) nanocomposite containing $3 \mathrm{wt} \%$ of GO well dispersed in a $97 \mathrm{wt} \%$ PVK matrix show excellent antibacterial properties without significant cytotoxicity to mammalian cells. Toxicity of PVK-GO was studied with planktonic microbial cells, biofilms, and NIH 3 T3 fibroblast cells against E. coli, Cupriavidus metallidurans, Bacillus subtilis, and Rhodococcus opacus. PVK-GO in solution was found to encapsulate the bacterial cells resulting in their reduced metabolic activity and death. ${ }^{149}$ Hydrazine reduction of the nanowalls was also found to be effective in increasing the magnitude of the cell membrane damage. Graphene oxide nanowalls (GONW) reduced by hydrazine were found to be more toxic to the bacteria than the unreduced 


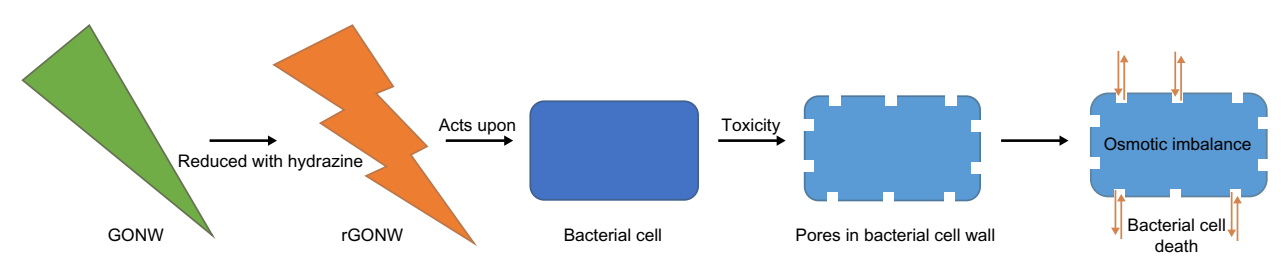

Figure I Possible mechanism of bacterial cell death with reduced GONW.

Abbreviations: GONW, graphene oxide nanowall; rGONW, reduced graphene oxide nanowall.

GONW. Figure 1 shows the possible mechanism for the death of the bacterial cell by GONWs reduced by hydrazine. Better antibacterial activity of the reduced nanowalls was found to be due to better charge transfer between the bacteria and more sharpened edges of the reduced nanowalls. ${ }^{132}$

The density of the edges of the graphene was one of the principal parameters that contributed to the antibacterial behavior of the graphene nanosheet films. Antibacterial mechanism involved the possible formation of pores in the bacterial cell wall, causing a subsequent osmotic imbalance leading to cell death. ${ }^{142}$ Nguyen et al ${ }^{150}$ investigated the antibacterial properties of GO against human intestinal bacteria and in vitro cytotoxicity using the Caco- 2 cell line derived from a colon carcinoma, but found no toxicity of GO at different concentrations $(10-500 \mu \mathrm{g} / \mathrm{mL})$ against the selected bacteria. Only a mild cytotoxic action on Caco-2 cells after 24 hours of exposure was observed suggesting its biocompatibility. Nanda et al ${ }^{151}$ determined the antibacterial property of cystamine-conjugated GO against four types of pathogenic bacteria. Minimum inhibitory concentration values were found to be $1 \mu \mathrm{g} / \mathrm{mL}$ against $E$. coli and Salmonella typhimurium, $6 \mu \mathrm{g} / \mathrm{mL}$ against Enterococcus faecalis, and $4 \mu \mathrm{g} / \mathrm{mL}$ against $B$. subtilis, suggesting the possible use of cystamine-conjugated GO nanohybrid in the treatment of dermatological disorders.

Peptide-conjugated GO membrane has been found to be efficient in the removal and effective killing of multiple drug-resistant bacteria. ${ }^{152}$ Similarly, Viraka Nellore et al ${ }^{83}$ reported the development of PGLa antimicrobial peptide and glutathione-conjugated CNT-bridged 3DGO membrane, which can be used for efficient disinfection of $E$. coli O157:H7 bacteria. Disinfection data indicated that the PGLaattached membrane enhances the possibility of destroying pathogenic E. coli via synergistic mechanism. Studies revealing the interaction between bacterial cell membranes and the surface of graphene have proposed that the grapheneinduced bacterial cell death is caused either by the insertion of blade-like graphene-based nanosheets or the destructive extraction of lipid molecules by the presence of the lipophilic graphene. ${ }^{142}$ Magnetic $\mathrm{Fe}_{3} \mathrm{O}_{4}$-graphene composite $\left(\mathrm{G}-\mathrm{Fe}_{3} \mathrm{O}_{4}\right)$ were also found efficient in removing a wide range of bacteria, including $S$. aureus, E. coli, Salmonella, E. faecium, E. faecalis, and Shigella. The removal efficiency of E. coli for was found to reach $93.09 \%$ as compared with $54.97 \%$ for pure $\mathrm{Fe}_{3} \mathrm{O}_{4}$ nanoparticles. ${ }^{153}$ The synergistic effects of $\mathrm{GO}$ and zinc oxide nanoparticles were found to give a superior antibacterial activity of the composites. ${ }^{154}$

\section{Toxicity to aquatic environments}

Systematic investigation of any potential toxic effects of GO in wastewater microbial communities is essential to determine the potential adverse effects and the fate of these nanomaterials in the environment. ${ }^{155} \mathrm{GFNs}$ including pristine graphene, rGO, and GO offer great application potential, leading to the possibility of their release into aquatic environments. Upon exposure, graphene/rGO and GO exhibit different adsorption properties toward environmental adsorbates. ${ }^{80}$ Ahmed and Rodrigues ${ }^{155}$ investigated the toxicity of GO on the microbial functions related to the biological wastewater treatment process and showed that toxic effects of GO on microbial communities were dose dependent, especially in concentrations between 50 and $300 \mathrm{mg} / \mathrm{L}$.

\section{Cytotoxicity and genotoxicity}

Studies are being conducted on the toxicity of graphene on different cell types and genetic material. Various recent studies include cytotoxicity factor of GFNs. ${ }^{140,156-158}$ In biological microenvironment, biomolecules bind onto nanoparticles forming corona and endow nanoparticles a new biological identity. ${ }^{157}$ Duan et al ${ }^{156}$ showed that the so-called "protein corona" formed in serum medium decreased the cellular uptake of GO, thus significantly mitigating its potential cytotoxicity. Molecular dynamic simulations also revealed that the adsorbed bovine serum albumin in effect weakened the interaction between the phospholipids and graphene surface due to reduction of the available surface area and an unfavorable steric effect, thus significantly reducing the graphene penetration and lipid bilayer damaging. Protein-coated GO were found to be markedly less cytotoxic than pristine and protein-coated single-walled carbon nanotubes (SWCNTs). ${ }^{157}$ 
GO nanosheets were suggested to intercalate efficiently into DNA molecules and GO sheets combining with copper ions were illustrated to cause scission of DNA. ${ }^{159}$ The scission of DNA by the $\mathrm{GO} / \mathrm{Cu}^{2+}$ system is critically dependent on the concentrations of $\mathrm{GO}$ and $\mathrm{Cu}^{2+}$ and their ratio. Similarly, $\mathrm{Wu}$ et $\mathrm{al}^{158}$ studied the potential cytotoxicity of GO nanosheets on human breast cancer MDA-MB-231 cell line and suggested that higher concentrations of GO ( $\geq 100 \mu \mathrm{g} / \mathrm{mL})$ exhibited time- and dose-dependent cytotoxicity against MDA-MB-231 cells. The exposure suppressed the colony-forming capacity and cellular proliferation. Even higher concentrations of GO increased the proportion of G0/G1 phase cells and resulted in higher generation of intracellular reactive oxygen species (ROS), which may be directly related to cytotoxicity. The paclitaxel-loaded composites were found to enter the A549 cancer cells and exert cytotoxicity. ${ }^{89}$ PEGylation of GO has shown to reduce or change its cytotoxicity. ${ }^{160-162}$ Lymphoma cells were treated with different concentrations $(10-100 \mu \mathrm{g} / \mathrm{mL})$ of PEGylated GO at different time points $(6,12$, and 24 hours), but a low toxicity to lymphoma cells was found suggesting a fair chance for the application of PEGylated GO in medicines. ${ }^{160} \mathrm{GO}$ has been found to present an attenuation effect on X-ray-induced genotoxicity in cultured lymphocytes. ${ }^{163}$ The effect of surface coatings on cytotoxicity of GFNs was studied. ${ }^{161}$ Naked GO could induce a significant toxicity to macrophages, while the coated GO with biocompatible macromolecules such as PEG or bovine serum albumin could greatly attenuate their toxicity. Qu et al ${ }^{164}$ found that QDs posed great damage to macrophages through intracellular accumulation of QDs coupled with ROS, particularly for QDs coated with PEG$\mathrm{NH}_{2}$. QDs modified with PEG-conjugated amine particles were found to exert robust inhibition on cell proliferation of J744A.1 macrophages. Graphene nanoplatelets (GNPs) synthesized using potassium permanganate-based oxidation and exfoliation followed by reduction with hydroiodic acid (rGNP-HI) were found to show excellent potential as biomodal contrast agents for magnetic resonance imaging and computed tomography. In vitro cytotoxicity analysis performed on NIH 3T3 mouse fibroblasts and A498 human kidney epithelial cells showed $\mathrm{CD}_{50}$ values of rGNP-HI to lie between 179 and $301 \mu \mathrm{g} / \mathrm{mL} .{ }^{165}$ The cell viability experiments revealed that the presence of the nanocomposites of GO with gold nanoparticles can significantly reduce the cytotoxicity of the amyloid peptides. ${ }^{166}$ GOs were also found to induce apoptosis of erythroid cells through oxidative stress in E14.5 fetal liver erythroid cells. ${ }^{164}$ Waiwijit et al ${ }^{167}$ assessed cytoxicities of MDA-MB-231 breast cancer cells (MDA cells) on carbon paste and graphene-carbon paste substrates. Cell viability on graphene-carbon paste substrate was found to initially increase as graphene content increased from 0 to $2.5 \mathrm{wt} \%$, but then decreased as the content increased further. Similarly, Wu et al ${ }^{168}$ evaluated the cytotoxicity on human multiple myeloma cells (RPMI-8226) treated with GO, doxorubicin (DOX), and GO loaded with DOX (GO/DOX) and revealed that cells treated with $\mathrm{GO}, \mathrm{DOX}$, and $\mathrm{GO} / \mathrm{DOX}$ for 24 hours showed a decrease in proliferation. GO/DOX was found to significantly inhibit cell proliferation as compared with pure DOX $(P<0.01)$. But purified GO as prepared and characterized in the study ${ }^{169}$ did not induce significant cytotoxic responses in vitro, or inflammation and granuloma formation in vivo. GO and carboxyl GNPs were found to cause dose- and time-dependent cytotoxicity in HepG2 cells with plasma membrane damage. But no toxicity was found when applied at very low concentrations $(<4 \mu \mathrm{g} / \mathrm{mL}) .{ }^{170}$ Cell division of Chlorella vulgaris was found to be promoted at 24 hours and then inhibited at 96 hours after GO and carboxyl single-walled carbon nanotube (C-SWCNT) exposure. At 96 hours, both GO and C-SWCNT inhibited the rates of cell division by $0.08 \%-15 \%$ and $0.8 \%-28.3 \%$, respectively. ${ }^{171}$ Table 2 shows different cytotoxic studies on graphene and its nanocomposites.

GQDs with their unique morphology and exceptional properties, hold great promise for many applications, especially in the biomedical field. ${ }^{178}$ Cytotoxicity of GQDs have been assessed by various researchers on erythroid cells and macrophages ${ }^{164}$ human gastric cancer MGC-803 and breast cancer MCF-7 cells, ${ }^{178}$ and human A549 lung carcinoma cells and human neural glioma C6 cells. ${ }^{179}$ Cytotoxicity of three kinds of GQDs with different modified groups $\left(\mathrm{NH}_{2}\right.$, $\mathrm{COOH}$, and $\mathrm{CO}-\mathrm{N}\left(\mathrm{CH}_{3}\right)_{2}$, respectively) in human A549 lung carcinoma cells and human neural glioma C6 cells was investigated using thiazoyl blue colorimetric (MTT) assay and trypan blue assay. GQDs were found to randomly disperse in the cytoplasm, but not get diffused into nucleus. The study suggested the three modified GQDs to have good biocompatibility even at the concentration of $200 \mu \mathrm{g} / \mathrm{mL} .{ }^{179} \mathrm{GQDs}$ were demonstrated to get internalized primarily through caveolae-mediated endocytosis and have lower toxicities as compared with micrometer-sized GO on the cell viability, internal cellular ROS level, mitochondrial membranes potential, and cell cycles. ${ }^{178}$

Genetic toxicity in animal models represents a potential health hazard that may lead to different health-related ailments including cancer. Oxidative stress is also known to cause toxicity. ${ }^{140}$ Different authors have shown that ROS formation 
Table 2 Comparative analysis of cytotoxicity of GFNs

\begin{tabular}{|c|c|c|c|}
\hline Sr no & Authors & Study material & Results \\
\hline I. & Ali-Boucetta et al ${ }^{169}$ & Purified GO dispersions & Purified GO did not induce significant cytotoxic responses \\
\hline 2. & Cai et $\mathrm{al}^{172}$ & Sodium I-naphthalenesulfonate-functionalized rGO & Low cytotoxicity and long-term antibacterial activity \\
\hline 3. & Du et $\mathrm{al}^{160}$ & PEGylated GO on lymphoma cells & $\begin{array}{l}\text { PEG-GO had excellent dispersion and low toxicity on } \\
\text { lymphoma cells }\end{array}$ \\
\hline 4. & Lammel et al ${ }^{170}$ & $\begin{array}{l}\text { GO and carboxyl graphene nanoplatelets in the } \\
\text { human hepatocellular carcinoma cell line HepG2 }\end{array}$ & $\begin{array}{l}\text { Dose- and time-dependent cytotoxicity in HepG2 cells; } \\
\text { plasma membrane damage and induction of oxidative } \\
\text { stress. No toxicity at low concentrations }(<4 \mu \mathrm{g} / \mathrm{mL})\end{array}$ \\
\hline 5. & Li et al ${ }^{166}$ & GO/gold nanocomposites & $\begin{array}{l}\text { Nanocomposites can significantly reduce the cytotoxicity of } \\
\text { the amyloid peptides }\end{array}$ \\
\hline 6. & Liao et al ${ }^{173}$ & $\begin{array}{l}\text { GO and graphene in human erythrocytes and skin } \\
\text { fibroblasts }\end{array}$ & $\begin{array}{l}\text { Graphene sheets are more damaging to mammalian } \\
\text { fibroblasts than GO. GO showed higher hemolytic activity } \\
\text { than graphene sheets. Coating GO with chitosan nearly } \\
\text { eliminated hemolytic activity }\end{array}$ \\
\hline 7. & Qu et al ${ }^{164}$ & QDs and GO to erythroid cells and macrophages & $\begin{array}{l}\text { QDs coupled with ROS are highly damaging to } \\
\text { macrophages, particularly QDs coated with PEG-NH} H_{2} \text { GO } \\
\text { could provoke apoptosis of erythroid cells }\end{array}$ \\
\hline 8. & Wang et al ${ }^{174}$ & GO on human lung fibroblast cells & $\begin{array}{l}\text { Surface charge on GO plays an important role in its toxicity } \\
\text { to HLF cells }\end{array}$ \\
\hline 9. & Wu et al ${ }^{158}$ & GO on human MDA-MB-23I cells & $\begin{array}{l}\text { Higher } \mathrm{GO} \text { concentrations increased } \mathrm{G}_{0} / \mathrm{G}_{\text {, }} \text { phase cell } \\
\text { proportion; induced LDH release and intracellular ROS } \\
\text { production }\end{array}$ \\
\hline 10. & Wu et al ${ }^{168}$ & GO and GO loaded with doxorubicin & $\begin{array}{l}\text { GO caused low cytotoxicity and did not induce cell } \\
\text { apoptosis or change the cell cycle in multiple myeloma cells }\end{array}$ \\
\hline II. & Yuan et al ${ }^{175}$ & $\begin{array}{l}\text { Oxidized SWCNTs and GO on human hepatoma } \\
\text { HepG } 2 \text { cells }\end{array}$ & $\begin{array}{l}\text { Oxidized SWCNTs induced oxidative stress; interfered } \\
\text { with intracellular metabolic routes, protein synthesis and } \\
\text { cytoskeletal systems; perturbed the cell cycle and significant } \\
\text { increase in the proportion of apoptotic cells }\end{array}$ \\
\hline 12. & Zhang et al ${ }^{176}$ & Uniform ultrasmall GO nanosheets & $\begin{array}{l}\text { Excellent biocompatibility; lower cytotoxicity, and higher } \\
\text { cellular uptake }\end{array}$ \\
\hline 13. & Zhang et $\mathrm{al}^{177}$ & GO & $\begin{array}{l}\text { GO reduced } \mathrm{Vpr} / 3-33 \text {-induced cytotoxicity to } \\
\text { neuroblastoma cells and } \mathrm{T} \text {-cells }\end{array}$ \\
\hline
\end{tabular}

Abbreviations: GFNs, graphene family nanomaterials; GO, graphene oxide; HLF, human lung fibroblast; LDH, lactate dehydrogenase; QD, quantum dot; rGO, reduced graphene oxide; ROS, reactive oxygen species; SWCNTs, single-walled carbon nanotubes; $\mathrm{Sr}$ no, serial number.

may be the indirect way of GFN cytotoxicity on different models. ${ }^{141,164,167,170,173-175,178,180}$ The authors have reported genotoxicity in lymphocyte cells, ${ }^{181}$ human stem cells, ${ }^{125}$ and human lung fibroblast cells. ${ }^{174}$ De et al ${ }^{182}$ studied genotoxicity of $\mathrm{GO}$ by varying its concentration and flake sizes. A 24-hour cytotoxicity test showed loss in the viability for A549. Comet assay showed a marked genotoxicity, which was found to be positively correlated with the concentration in case of micrometer-sized GO flakes while for nanometer-sized GO flakes, a high degree of genotoxicity was found at the lowest concentration tested. Genotoxicity of GO to human lung fibroblast cells was also reported to be concentration dependent. ${ }^{174}$ Genotoxicity was predicted to be a result of GO-mediated oxidative stress. PVK-GO nanocomposites were found to have no significant cytotoxicity to mammalian cells yet have good antibacterial properties. ${ }^{149}$ Different factors, especially the oxidation degree of GOs, affect their toxicity. Zhang et al ${ }^{140}$ evaluated the cytotoxicity of three GO samples with varied oxidation degrees on mouse embryo fibroblasts and found that as the oxidation degree decreased, GO derivatives led to a higher degree of cytotoxicity and apoptosis. On the contrary, $\mathrm{Na}$ et al ${ }^{183}$ evaluated the cytoprotective effect of GO and showed that GO can protect cells from internalization of toxic hydrophobic molecules, nanoparticles, and nucleic acids such as small interfering RNA and plasmid DNA by interacting with cell surface lipid bilayers.

\section{Oxidative stress}

Oxidative stress can damage proteins, DNA, and lipids, and is involved in the progression of many diseases. Damage to infected cells caused by oxidative stress is related to increased levels of ROS. During oxidative stress, hydrogen peroxide levels are often increased and catalase levels are decreased inside cells. ${ }^{151}$ Induction of oxidative stress is a known mode of cellular toxicity. Higher oxidative stress levels may induce cytotoxicity as well as genotoxicity and be involved in formation of incipient tumor and carcinomatous cells. ${ }^{184}$ Many recent studies have revealed the potential of 
various nanoparticles to induce oxidative stress ${ }^{185-192}$ and some studies also investigated the alleviating effect of different nanoparticles on oxidative stress induced by ethanol and D-galactosamine and lipopolysaccharide. ${ }^{193,194}$ Similarly, many researchers have also conducted studies on the oxidative stress aspect of GFNs. ${ }^{140,164,174,175,180}$ GO and carboxyl graphene accumulation in the cytosol was found to increase intracellular ROS levels in HepG2 cells. ${ }^{170} \mathrm{GO}$ treatment has also been found to reduce the production of X-ray-induced ROS among fibroblasts. ${ }^{163}$

Liu et al ${ }^{195}$ proposed a three-step antimicrobial mechanism for graphene-based materials, including initial cell deposition on graphene-based materials, membrane stress caused by direct contact with sharp nanosheets, and the ensuing superoxide anion-independent oxidation. In a recent study, ${ }^{140}$ GOs with three different oxidation degrees stimulated a dramatic increase in the production of ROS in mouse embryo fibroblasts. The less oxidized GO produced a higher level of ROS, suggesting the major role of oxidative stress in the oxidation-dependent toxicity of GOs. Electron spin resonance spectrometry showed a strong association of the lower oxidation degree of GOs with their stronger indirect oxidative damage through $\mathrm{H}_{2} \mathrm{O}_{2}$ decomposition into $\mathrm{OH}$ and higher direct oxidative abilities on cells. Similarly, C-SWCNTexposed cells exhibited higher ROS levels than GO-exposed cells. The metabolism of alkanes, lysine, octadecadienoic acid, and valine was found to be associated with ROS production and were regarded as new biomarkers of ROS. ${ }^{171}$ Nanda et al ${ }^{151}$ produced a cystamine-conjugated $\mathrm{GO}$, which resulted in low cytotoxicity but a strong ROS effect. The electronic charge on the surface of GO was suggested to play a very important role in oxidative stress-mediated toxicity of GO to human lung fibroblast cells. ${ }^{174}$ Similarly, exposure of Pseudomonas aeruginosa to GO and rGO was found to induce a significant production of superoxide radical anion. ${ }^{196}$

\section{Conclusion}

Graphene is emerging as a dynamic nanocarbon. Despite a wide scope and numerous advantages of graphene and its nanocomposites in different fields of scientific world, it also poses toxic effects on different biological models as described in the paper. After reviewing the literature in relation to the possible toxic effects posed by the graphene and its composite forms, it can be summarized that using graphene as a modular transport material among biological systems including humans, it is highly suggestive of checking their toxicity to varied cellular types. Even mild toxicity factors should not be ignored. Research in the field of applications and toxicity of graphene is going on, but the author is of the view that further research in coming times will surely open up new gateways for use of graphene-based nanomaterials in newer fields of biological, physical, and chemical sciences.

\section{Disclosure}

The author reports no conflicts of interest in this work.

\section{References}

1. Novoselov KS, Geim AK, Morozov SV, et al. Electric field effect in atomically thin carbon films. Science. 2004;306(5696):666-669.

2. Sanchez VC, Jachak A, Hurt RH, Kane AB. Biological interactions of graphene-family nanomaterials: an interdisciplinary review. Chem Res Toxicol. 2012;25(1):15-34.

3. Benitez-Martinez S, Valcarcel M. Graphene quantum dots in analytical science. Trac Trend Anal Chem. 2015;72:93-113.

4. Hill MR, MacKrell EJ, Forsthoefel CP, et al. Biodegradable and $\mathrm{pH}$-responsive nanoparticles designed for site-specific delivery in agriculture. Biomacromolecules. 2015;16(4):1276-1282.

5. Mishra S, Singh HB. Biosynthesized silver nanoparticles as a nanoweapon against phytopathogens: exploring their scope and potential in agriculture. Appl Microbiol Biotechnol. 2015;99(3):1097-1107.

6. Sabir S, Arshad M, Chaudhari SK. Zinc oxide nanoparticles for revolutionizing agriculture: synthesis and applications. ScientificWorldJournal. 2014;2014:925494.

7. Cota-Arriola O, Cortez-Rocha MO, Burgos-Hernandez A, EzquerraBrauer JM, Plascencia-Jatomea M. Controlled release matrices and micro/nanoparticles of chitosan with antimicrobial potential: development of new strategies for microbial control in agriculture. J Sci Food Agric. 2013;93(7):1525-1536.

8. Becaro AA, Puti FC, Correa DS, Paris EC, Marconcini JM, Ferreira MD. Polyethylene films containing silver nanoparticles for applications in food packaging: characterization of physico-chemical and anti-microbial properties. $J$ Nanosci Nanotechnol. 2015;15(3): $2148-2156$.

9. Pathak L, Kanwal A, Agrawal Y. Curcumin loaded self-assembled lipidbiopolymer nanoparticles for functional food applications. J Food Sci Technol. 2015;52(10):6143-6156.

10. Roushani M, Abbasi S, Khani H. Synthesis and application of ionimprinted polymer nanoparticles for the extraction and preconcentration of mercury in water and food samples employing cold vapor atomic absorption spectrometry. Environ Monit Assess. 2015;187(9):4820.

11. Krishnaraj C, Harper SL, Choe HS, Kim KP, Yun SI. Mechanistic aspects of biologically synthesized silver nanoparticles against foodand water-borne microbes. Bioprocess Biosyst Eng. 2015;38(10): 1943-1958.

12. Ruiz-Palomero C, Soriano ML, Valcarcel M. Sulfonated nanocellulose for the efficient dispersive micro solid-phase extraction and determination of silver nanoparticles in food products. $J$ Chromatogr A. 2016;1428:352-358.

13. Song ZM, Chen N, Liu JH, et al. Biological effect of food additive titanium dioxide nanoparticles on intestine: an in vitro study. $J \mathrm{Appl}$ Toxicol. 2015;35(10):1169-1178.

14. Jacobs R, van der Voet H, Ter Braak CJ. Integrated probabilistic risk assessment for nanoparticles: the case of nanosilica in food. J Nanopart Res. 2015;17(6):251.

15. Wang H, Guo X, Fu S, Yang T, Wen Y, Yang H. Optimized coreshell Au@Ag nanoparticles for label-free Raman determination of trace Rhodamine B with cancer risk in food product. Food Chem. 2015;188:137-142.

16. Lichtenstein D, Ebmeyer J, Knappe P, et al. Impact of food components during in vitro digestion of silver nanoparticles on cellular uptake and cytotoxicity in intestinal cells. Biol Chem. 2015;396(11): $1255-1264$. 
17. Secor EB, Ahn BY, Gao TZ, Lewis JA, Hersam MC. Rapid and versatile photonic annealing of graphene inks for flexible printed electronics. Adv Mater. 2015;26(26):4533-4538.

18. Chung Y, Kim HH, Lee S, et al. Ubiquitous graphene electronics on scotch tape. Sci Rep. 2015;5:12575.

19. Sanders S, Cabrero-Vilatela A, Kidambi PR, et al. Engineering high charge transfer n-doping of graphene electrodes and its application to organic electronics. Nanoscale. 2015;7(30):13135-13142.

20. Xie B, Yang C, Zhang Z, et al. Shape-tailorable graphene-based ultra-high-rate supercapacitor for wearable electronics. ACS Nano. 2015;9(6):5636-5645.

21. Asadi K, Timmering EC, Geuns TC, et al. Up-scaling graphene electronics by reproducible metal-graphene contacts. ACS Appl Mater Interfaces. 2015;7(18):9429-9435.

22. Amani M, Burke RA, Proie RM, Dubey M. Flexible integrated circuits and multifunctional electronics based on single atomic layers of MoS2 and graphene. Nanotechnology. 2015;26(11):115202.

23. Shiue RJ, Gao Y, Wang Y, et al. High-responsivity graphene-boron nitride photodetector and autocorrelator in a silicon photonic integrated circuit. Nano Lett. 2015;15(11):7288-7293.

24. Shi E, Li H, Yang L, et al. Carbon nanotube network embroidered graphene films for monolithic all-carbon electronics. Adv Mater. 2015;27(4):682-688.

25. Hlaing $\mathrm{H}$, Kim $\mathrm{CH}$, Carta F, et al. Low-voltage organic electronics based on a gate-tunable injection barrier in vertical graphene-organic semiconductor heterostructures. Nano Lett. 2015;15(1):69-74.

26. Liang J, Chen Y, Xu Y, et al. Toward all-carbon electronics: fabrication of graphene-based flexible electronic circuits and memory cards using maskless laser direct writing. ACS Appl Mater Interfaces. 2010;2(11):3310-3317.

27. Georgiou T, Jalil R, Belle BD, et al. Vertical field-effect transistor based on graphene-WS2 heterostructures for flexible and transparent electronics. Nat Nanotechnol. 2013;8(2):100-103.

28. Lee IY, Park HY, Park JH, et al. Poly-4-vinylphenol and poly (melamine-co-formaldehyde)-based graphene passivation method for flexible, wearable and transparent electronics. Nanoscale. 2014;6(7):3830-3836.

29. Secor EB, Lim S, Zhang H, Frisbie CD, Francis LF, Hersam MC. Gravure printing of graphene for large-area flexible electronics. $A d v$ Mater. 2014;26(26):4533-4538.

30. Hyun WJ, Secor EB, Hersam MC, Frisbie CD, Francis LF. Highresolution patterning of graphene by screen printing with a silicon stencil for highly flexible printed electronics. Adv Mater. 2015;27(1): 109-115.

31. Meng J, Chen JJ, Zhang L, Bie YQ, Liao ZM, Yu DP. Vertically architectured stack of multiple graphene field-effect transistors for flexible electronics. Small. 2015;11(14):1660-1664.

32. Han SJ, Garcia AV, Oida S, Jenkins KA, Haensch W. Graphene radio frequency receiver integrated circuit. Nat Commun. 2014;5:3086.

33. Lin YM, Valdes-Garcia A, Han SJ, et al. Wafer-scale graphene integrated circuit. Science. 2011;332(6035):1294-1297.

34. Ajayi OA, Guitierrez DH, Peaslee D, et al. Electrophoretically deposited graphene oxide and carbon nanotube composite for electrochemical capacitors. Nanotechnology. 2015;26(41):415203.

35. Surwade SP, Smirnov SN, Vlassiouk IV, et al. Water desalination using nanoporous single-layer graphene. Nat Nanotechnol. 2015;10(5): $459-464$.

36. Cohen-Tanugi D, Grossman JC. Mechanical strength of nanoporous graphene as a desalination membrane. Nano Lett. 2014;14(11): 6171-6178

37. Cohen-Tanugi D, Grossman JC. Water permeability of nanoporous graphene at realistic pressures for reverse osmosis desalination. JChem Phys. 2014;141(7):074704

38. Nicolai A, Sumpter BG, Meunier V. Tunable water desalination across graphene oxide framework membranes. Phys Chem Chem Phys. 2014;16(18):8646-8654.
39. Konatham D, Yu J, Ho TA, Striolo A. Simulation insights for graphene-based water desalination membranes. Langmuir. 2013; 29(38):11884-11897.

40. Wang EN, Karnik R. Water desalination: graphene cleans up water. Nat Nanotechnol. 2012;7(9):552-554.

41. Cohen-Tanugi D, Grossman JC. Water desalination across nanoporous graphene. Nano Lett. 2012;12(7):3602-3608.

42. Oyefusi A, Olanipekun O, Neelgund GM, et al. Hydroxyapatite grafted carbon nanotubes and graphene nanosheets: promising bone implant materials. Spectrochim Acta A Mol Biomol Spectrosc. 2014;132:410-416.

43. La WG, Jin M, Park S, et al. Delivery of bone morphogenetic protein-2 and substance $\mathrm{P}$ using graphene oxide for bone regeneration. Int $J$ Nanomedicine. 2014;9(1):107-116.

44. Gu M, Liu Y, Chen T, et al. Is graphene a promising nano-material for promoting surface modification of implants or scaffold materials in bone tissue engineering? Tissue Eng Part B Rev. 2014;20(5):477-491.

45. La WG, Park S, Yoon HH, et al. Delivery of a therapeutic protein for bone regeneration from a substrate coated with graphene oxide. Small. 2013;9(23):4051-4060.

46. Goncalves G, Cruz SM, Ramalho A, Gracio J, Marques PA. Graphene oxide versus functionalized carbon nanotubes as a reinforcing agent in a PMMA/HA bone cement. Nanoscale. 2012;4(9):2937-2945.

47. Dinescu S, Ionita M, Pandele AM, et al. In vitro cytocompatibility evaluation of chitosan/graphene oxide 3D scaffold composites designed for bone tissue engineering. Biomed Mater Eng. 2014;24(6):2249-2256.

48. Li Z, Wang H, Yang B, Sun Y, Huo R. Three-dimensional graphene foams loaded with bone marrow derived mesenchymal stem cells promote skin wound healing with reduced scarring. Mater Sci Eng C Mater Biol Appl. 2015;57:181-188.

49. Dubey N, Bentini R, Islam I, Cao T, Castro Neto AH, Rosa V. Graphene: A Versatile Carbon-Based Material for Bone Tissue Engineering. Stem Cells Int. 2015;2015:804213.

50. Elkhenany H, Amelse L, Lafont A, et al. Graphene supports in vitro proliferation and osteogenic differentiation of goat adult mesenchymal stem cells: potential for bone tissue engineering. J Appl Toxicol. 2015;35(4):367-374.

51. Feng ZQ, Wang T, Zhao B, Li J, Jin L. Soft graphene nanofibers designed for the acceleration of nerve growth and development. Adv Mater. Epub 2015 Sep 24.

52. Lopez-Dolado E, Gonzalez-Mayorga A, Portoles MT, et al. Neural regeneration: subacute tissue response to $3 \mathrm{D}$ graphene oxide scaffolds implanted in the injured rat spinal cord. Adv Healthc Mater. 2015;4(12):1892.

53. Zhang C, Wang L, Zhai T, Wang X, Dan Y, Turng LS. The surface grafting of graphene oxide with poly(ethylene glycol) as a reinforcement for poly(lactic acid) nanocomposite scaffolds for potential tissue engineering applications. J Mech Behav Biomed Mater. 2015;53:403-413.

54. Liao J, Qu Y, Chu B, Zhang X, Qian Z. Biodegradable CSMA/PECA/ graphene porous hybrid scaffold for cartilage tissue engineering. $S c i$ Rep. 2015;5:9879.

55. Kumar S, Chatterjee K. Strontium eluting graphene hybrid nanoparticles augment osteogenesis in a 3D tissue scaffold. Nanoscale. 2015;7(5):2023-2033.

56. Rahman M, Ahmad MZ, Ahmad J et al. Role of graphene nanocomposites in cancer therapy: theranostic applications, metabolic fate and toxicity issues. Curr Drug Metab. 2014;16(5):397-409.

57. Azimzadeh M, Rahaie M, Nasirizadeh N, Ashtari K, Naderi-Manesh $\mathrm{H}$. An electrochemical nanobiosensor for plasma miRNA-155, based on graphene oxide and gold nanorod, for early detection of breast cancer. Biosens Bioelectron. 2015;77:99-106.

58. Abdurhman AA, Zhang Y, Zhang G, Wang S. Hierarchical nanostructured noble metal/metal oxide/graphene-coated carbon fiber: in situ electrochemical synthesis and use as microelectrode for real-time molecular detection of cancer cells. Anal Bioanal Chem. 2015;407(26):8129-8136. 
59. Gu Y, Ju C, Li Y, et al. Detection of circulating tumor cells in prostate cancer based on carboxylated graphene oxide modified light addressable potentiometric sensor. Biosens Bioelectron. 2015;66:24-31.

60. Lin CW, Wei KC, Liao SS, et al. A reusable magnetic graphene oxidemodified biosensor for vascular endothelial growth factor detection in cancer diagnosis. Biosens Bioelectron. 2015;67:431-437.

61. Bi S, Zhao T, Jia X, He P. Magnetic graphene oxide-supported hemin as peroxidase probe for sensitive detection of thiols in extracts of cancer cells. Biosens Bioelectron. 2014;57:110-116.

62. Al-Ogaidi I, Gou H, Aguilar ZP, et al. Detection of the ovarian cancer biomarker CA-125 using chemiluminescence resonance energy transfer to graphene quantum dots. Chem Commun (Camb). 2014;50(11):1344-1346.

63. Guo R, Zhou S, Li Y, Li X, Fan L, Voelcker NH. Rhodaminefunctionalized graphene quantum dots for detection of $\mathrm{Fe} 3+$ in cancer stem cells. ACS Appl Mater Interfaces. 2015;7(43):23958-23966.

64. Li P, Zhang B, Cui T. Towards intrinsic graphene biosensor: a label-free, suspended single crystalline graphene sensor for multiplex lung cancer tumor markers detection. Biosens Bioelectron. 2015;72:168-174.

65. Maji SK, Mandal AK, Nguyen KT, Borah P, Zhao Y. Cancer cell detection and therapeutics using peroxidase-active nanohybrid of gold nanoparticle-loaded mesoporous silica-coated graphene. ACS Appl Mater Interfaces. 2015;7(18):9807-9816.

66. Yim D, Kang H, Jeon SJ, et al. Graphene oxide-encoded Ag nanoshells with single-particle detection sensitivity towards cancer cell imaging based on SERRS. Analyst. 2015;140(10):3362-3367.

67. Ma H, Zhang X, Li X, Li R, Du B, Wei Q. Electrochemical immunosensor for detecting typical bladder cancer biomarker based on reduced graphene oxide-tetraethylene pentamine and trimetallic AuPdPt nanoparticles. Talanta. 2015;143:77-82.

68. Jin B, Wang P, Mao H, et al. Multi-nanomaterial electrochemical biosensor based on label-free graphene for detecting cancer biomarkers. Biosens Bioelectron. 2014;55:464-469.

69. Wu D, Guo A, Guo Z, Xie L, Wei Q, Du B. Simultaneous electrochemical detection of cervical cancer markers using reduced graphene oxidetetraethylene pentamine as electrode materials and distinguishable redox probes as labels. Biosens Bioelectron. 2014;54:634-639.

70. Chen X, Jia X, Han J, Ma J, Ma Z. Electrochemical immunosensor for simultaneous detection of multiplex cancer biomarkers based on graphene nanocomposites. Biosens Bioelectron. 2013;50:356-361.

71. Li H, He J, Li S, Turner AP. Electrochemical immunosensor with N-doped graphene-modified electrode for label-free detection of the breast cancer biomarker CA 15-3. Biosens Bioelectron. 2013;43:25-29.

72. WuY, Xue P, Kang Y, Hui KM. Paper-based microfluidic electrochemical immunodevice integrated with nanobioprobes onto graphene film for ultrasensitive multiplexed detection of cancer biomarkers. Anal Chem. 2013;85(18):8661-8668

73. Cheng Y, Yuan R, Chai Y, et al. Highly sensitive luminol electrochemiluminescence immunosensor based on $\mathrm{ZnO}$ nanoparticles and glucose oxidase decorated graphene for cancer biomarker detection. Anal Chim Acta. 2012;745:137-142.

74. Liu F, Zhang Y, Ge S, et al. Magnetic graphene nanosheets based electrochemiluminescence immunoassay of cancer biomarker using CdTe quantum dots coated silica nanospheres as labels. Talanta. 2012;99:512-519.

75. Myung S, Solanki A, Kim C, Park J, Kim KS, Lee KB. Grapheneencapsulated nanoparticle-based biosensor for the selective detection of cancer biomarkers. Adv Mater. 2011;23(19):2221-2225.

76. Xu S, Liu Y, Wang T, Li J. Positive potential operation of a cathodic electrogenerated chemiluminescence immunosensor based on luminol and graphene for cancer biomarker detection. Anal Chem. 2011;83(10):3817-3823.

77. Du D, Zou Z, Shin Y, et al. Sensitive immunosensor for cancer biomarker based on dual signal amplification strategy of graphene sheets and multienzyme functionalized carbon nanospheres. Anal Chem. 2010;82(7):2989-2995.
78. Saeed LM, Mahmood M, Pyrek SJ, et al. Single-walled carbon nanotube and graphene nanodelivery of gambogic acid increases its cytotoxicity in breast and pancreatic cancer cells. J Appl Toxicol. 2014;34(11):1188-1199.

79. Zhang Y, Liu Y, Wang X, et al. Porous graphene oxide/carboxymethyl cellulose monoliths, with high metal ion adsorption. Carbohydr Polym. 2014;101:392-400.

80. Zhao J, Wang Z, White JC, Xing B. Graphene in the aquatic environment: adsorption, dispersion, toxicity and transformation. Environ Sci Technol. 2014;48(17):9995-10009.

81. Zhao ZQ, Chen X, Yang Q, Liu JH, Huang XJ. Selective adsorption toward toxic metal ions results in selective response: electrochemical studies on a polypyrrole/reduced graphene oxide nanocomposite. Chem Commun (Camb). 2012;48(16):2180-2182.

82. Willemse CM, Tlhomelang K, Jahed N, Baker PG, Iwuoha EI. Metallographene nanocomposite electrocatalytic platform for the determination of toxic metal ions. Sensors (Basel). 2011;11(4):3970-3987.

83. Viraka Nellore BP, Kanchanapally R, Pedraza F, et al. Bio-conjugated CNT-bridged 3D porous graphene oxide membrane for highly efficient disinfection of pathogenic bacteria and removal of toxic metals from water. ACS Appl Mater Interfaces. 2015;7(34):19210-19218.

84. Deng D, Jiang X, Yang L, Hou X, Zheng C. Organic solvent-free cloud point extraction-like methodology using aggregation of graphene oxide. Anal Chem. 2014;86(1):758-765.

85. An JH, Park SJ, Kwon OS, Bae J, Jang J. High-performance flexible graphene aptasensor for mercury detection in mussels. ACS Nano. 2013;7(12):10563-10571.

86. Henriques B, Goncalves G, Emami N, Pereira E, Vila M, Marques PA. Optimized graphene oxide foam with enhanced performance and high selectivity for mercury removal from water. $J$ Hazard Mater. 2015;301:453-461.

87. Weaver CL, LaRosa JM, Luo X, Cui XT. Electrically controlled drug delivery from graphene oxide nanocomposite films. ACS Nano. 2014;8(2):1834-1843.

88. Chowdhury SM, Surhland C, Sanchez Z, et al. Graphene nanoribbons as a drug delivery agent for lucanthone mediated therapy of glioblastoma multiforme. Nanomedicine. 2015;11(1):109-118.

89. Angelopoulou A, Voulgari E, Diamanti EK, Gournis D, Avgoustakis K. Graphene oxide stabilized by PLA-PEG copolymers for the controlled delivery of paclitaxel. Eur J Pharm Biopharm. 2015;93:18-26.

90. Chen H, Wang Z, Zong S, et al. A graphene quantum dot-based FRET system for nuclear-targeted and real-time monitoring of drug delivery. Nanoscale. 2015;7(37):15477-15486.

91. Dong H, Dai W, Ju H, et al. Multifunctional poly(L-lactide)-polyethylene glycol-grafted graphene quantum dots for intracellular MicroRNA imaging and combined specific-gene-targeting agents delivery for improved therapeutics. ACS Appl Mater Interfaces. 2015;7(20): $11015-11023$

92. Hsieh CJ, Chen YC, Hsieh PY, et al. Graphene oxide based nanocarrier combined with a $\mathrm{pH}$-sensitive tracer: a vehicle for concurrent $\mathrm{pH}$ sensing and $\mathrm{pH}$-responsive oligonucleotide delivery. ACS Appl Mater Interfaces. 2015;7(21):11467-11475.

93. Imani R, Emami SH, Faghihi S. Synthesis and characterization of an octaarginine functionalized graphene oxide nano-carrier for gene delivery applications. Phys Chem Chem Phys. 2015;17(9): 6328-6339.

94. Jiang T, Sun W, Zhu Q, et al. Furin-mediated sequential delivery of anticancer cytokine and small-molecule drug shuttled by graphene. Adv Mater. 2015;27(6):1021-1028.

95. Liu K, Wang Y, Li H, Duan Y. A facile one-pot synthesis of starch functionalized graphene as nano-carrier for $\mathrm{pH}$ sensitive and starch-mediated drug delivery. Colloids Surf B Biointerfaces. 2015;128:86-93.

96. Li J, Lyv Z, Li Y, et al. A theranostic prodrug delivery system based on $\mathrm{Pt}(\mathrm{IV})$ conjugated nano-graphene oxide with synergistic effect to enhance the therapeutic efficacy of Pt drug. Biomaterials. 2015;51:12-21. 
97. Song T, Gu K, Wang W, et al. Prolonged suppression of neuropathic pain by sequential delivery of lidocaine and thalidomide drugs using PEGylated graphene oxide. J Pharm Sci. 2015;104(11):3851-3860.

98. Xu H, Fan M, Elhissi AM, et al. PEGylated graphene oxide for tumor-targeted delivery of paclitaxel. Nanomedicine (Lond). 2015;10(8):1247-1262.

99. Xu Z, Zhu S, Wang M, Li Y, Shi P, Huang X. Delivery of paclitaxel using PEGylated graphene oxide as a nanocarrier. ACS Appl Mater Interfaces. 2015;7(2):1355-1363.

100. Chen J, Liu H, Zhao C, et al. One-step reduction and PEGylation of graphene oxide for photothermally controlled drug delivery. Biomaterials. 2014;35(18):4986-4995.

101. Mianehrow H, Moghadam MH, Sharif F, Mazinani S. Graphene-oxide stabilization in electrolyte solutions using hydroxyethyl cellulose for drug delivery application. Int J Pharm. 2015;484(1-2):276-282.

102. Mo R, Jiang T, Sun W, Gu Z. ATP-responsive DNA-graphene hybrid nanoaggregates for anticancer drug delivery. Biomaterials. 2015;50:67-74.

103. Tang Y, Hu H, Zhang MG, et al. An aptamer-targeting photoresponsive drug delivery system using "off-on" graphene oxide wrapped mesoporous silica nanoparticles. Nanoscale. 2015;7(14):6304-6310.

104. Wang X, Sun X, Lao J et al. Multifunctional graphene quantum dots for simultaneous targeted cellular imaging and drug delivery. Colloids Surf B Biointerfaces. 2014;122:638-644.

105. Wang H, Gu W, Xiao N, Ye L, Xu Q. Chlorotoxin-conjugated graphene oxide for targeted delivery of an anticancer drug. Int J Nanomedicine. 2014;9:1433-1442.

106. Wang Y, Polavarapu L, Liz-Marzan LM. Reduced graphene oxidesupported gold nanostars for improved SERS sensing and drug delivery. ACS Appl Mater Interfaces. 2014;6(24):21798-21805.

107. Wang C, Chen B, Zou M, Cheng G. Cyclic RGD-modified chitosan/ graphene oxide polymers for drug delivery and cellular imaging. Colloids Surf B Biointerfaces. 2014;122:332-340.

108. Song E, Han W, Li C et al. Hyaluronic acid-decorated graphene oxide nanohybrids as nanocarriers for targeted and $\mathrm{pH}$-responsive anticancer drug delivery. ACS Appl Mater Interfaces. 2014;6(15): 11882-11890.

109. Ou J, Wang F, Huang Y, et al. Fabrication and cyto-compatibility of Fe3O4/SiO2/graphene-CdTe QDs/CS nanocomposites for drug delivery. Colloids Surf B Biointerfaces. 2014;117:466-472.

110. Liu X, Ma D, Tang H, et al. Polyamidoamine dendrimer and oleic acidfunctionalized graphene as biocompatible and efficient gene delivery vectors. ACS Appl Mater Interfaces. 2014;6(11):8173-8183.

111. Kim H, Kim WJ. Photothermally controlled gene delivery by reduced graphene oxide-polyethylenimine nanocomposite. Small. 2014;10(1):117-126

112. You P, Yang Y, Wang M, Huang X, Huang X. Graphene oxide-based nanocarriers for cancer imaging and drug delivery. Curr Pharm Des. 2015;21(22):3215-3222.

113. Rahmanian N, Hamishehkar H, Dolatabadi JE, Arsalani N. Nano graphene oxide: a novel carrier for oral delivery of flavonoids. Colloids Surf B Biointerfaces. 2014;123:331-338.

114. Yang Y, Shi H, Wang Y, et al. Graphene oxide/manganese ferrite nanohybrids for magnetic resonance imaging, photothermal therapy and drug delivery. J Biomater Appl. 2016;30(6):810-822.

115. Wu J, Chen A, Qin M, et al. Hierarchical construction of a mechanically stable peptide-graphene oxide hybrid hydrogel for drug delivery and pulsatile triggered release in vivo. Nanoscale. 2015;7(5):1655-1660.

116. Wu QY, Lan JH, Wang CZ, Zhao YL, Chai ZF, Shi WQ. Understanding the interactions of neptunium and plutonium ions with graphene oxide: scalar-relativistic DFT investigations. J Phys Chem A. 2014;118(44):10273-10280.

117. Song W, Wang X, Wang Q, Shao D, Wang X. Plasma-induced grafting of polyacrylamide on graphene oxide nanosheets for simultaneous removal of radionuclides. Phys Chem Chem Phys. 2015;17(1):398-406.
118. Wu QY, Lan JH, Wang CZ, et al. Understanding the bonding nature of uranyl ion and functionalized graphene: a theoretical study. J Phys Chem A. 2014;118(11):2149-2158.

119. Romanchuk AY, Slesarev AS, Kalmykov SN, Kosynkin DV, Tour JM. Graphene oxide for effective radionuclide removal. Phys Chem Chem Phys. 2013;15(7):2321-2327.

120. Zhang Y, Petibone D, Xu Y, et al. Toxicity and efficacy of carbon nanotubes and graphene: the utility of carbon-based nanoparticles in nanomedicine. Drug Metab Rev. 2014;46(2):232-246.

121. Kang SM, Kim TH, Choi JW. Cell chip to detect effects of graphene oxide nanopellet on human neural stem cell. J Nanosci Nanotechnol. 2012;12(7):5185-5190.

122. Liu XT, Mu XY, Wu XL, et al. Toxicity of multi-walled carbon nanotubes, graphene oxide, and reduced graphene oxide to zebrafish embryos. Biomed Environ Sci. 2014;27(9):676-683.

123. Nurunnabi M, Khatun Z, Huh KM, et al. In vivo biodistribution and toxicology of carboxylated graphene quantum dots. ACS Nano. 2013;7(8):6858-6867.

124. Sasidharan A, Panchakarla LS, Chandran P, et al. Differential nanobio interactions and toxicity effects of pristine versus functionalized graphene. Nanoscale. 2011;3(6):2461-2464.

125. Akhavan O, Ghaderi E, Akhavan A. Size-dependent genotoxicity of graphene nanoplatelets in human stem cells. Biomaterials. 2012;33(32):8017-8025.

126. Fiorillo M, Verre AF, Iliut M, et al. Graphene oxide selectively targets cancer stem cells, across multiple tumor types: implications for nontoxic cancer treatment, via "differentiation-based nano-therapy". Oncotarget. 2015;6(6):3553-3562.

127. Rodriguez-Lozano FJ, Garcia-Bernal D, Aznar-Cervantes S, et al. Effects of composite films of silk fibroin and graphene oxide on the proliferation, cell viability and mesenchymal phenotype of periodontal ligament stem cells. J Mater Sci Mater Med. 2014;25(12): 2731-2741.

128. Chong $\mathrm{Y}$, Ma $\mathrm{Y}$, Shen $\mathrm{H}$, et al. The in vitro and in vivo toxicity of graphene quantum dots. Biomaterials. 2014;35(19):5041-5048.

129. Mao H, Chen W, Laurent S, et al. Hard corona composition and cellular toxicities of the graphene sheets. Colloids Surf B Biointerfaces. 2013;109:212-218.

130. Chatterjee N, Eom HJ, Choi J. A systems toxicology approach to the surface functionality control of graphene-cell interactions. Biomaterials. 2014;35(4):1109-1127.

131. Yuan J, Gao H, Ching CB. Comparative protein profile of human hepatoma HepG2 cells treated with graphene and single-walled carbon nanotubes: an iTRAQ-coupled 2D LC-MS/MS proteome analysis. Toxicol Lett. 2011;207(3):213-221.

132. Akhavan O, Ghaderi E. Toxicity of graphene and graphene oxide nanowalls against bacteria. ACS Nano. 2010;4(10):5731-5736.

133. Tang J, Chen Q, Xu L, et al. Graphene oxide-silver nanocomposite as a highly effective antibacterial agent with species-specific mechanisms. ACS Appl Mater Interfaces. 2013;5(9):3867-3874.

134. Siddique YH, Fatima A, Jyoti S, et al. Evaluation of the toxic potential of graphene copper nanocomposite (GCNC) in the third instar larvae of transgenic Drosophila melanogaster (hsp70-lacZ)Bg(9.). PLoS One. 2013;8(12):e80944.

135. Siddique YH, Khan W, Khanam S, Jyoti S, et al. Toxic potential of synthesized graphene zinc oxide nanocomposite in the third instar larvae of transgenic Drosophila melanogaster (hsp70-lacZ)Bg9. Biomed Res Int. 2014;2014:382124.

136. Wang ZG, Zhou R, Jiang D, et al. Toxicity of graphene quantum dots in zebrafish embryo. Biomed Environ Sci. 2015;28(5): 341-351.

137. Pretti C, Oliva M, Pietro RD, et al. Ecotoxicity of pristine graphene to marine organisms. Ecotoxicol Environ Saf. 2014;101: 138-145.

138. Han SG, Kim JK, Shin JH, et al. Pulmonary responses of SpragueDawley rats in single inhalation exposure to graphene oxide nanomaterials. Biomed Res Int. 2015;2015:376756. 
139. Wan B, Wang ZX, Lv QY, et al. Single-walled carbon nanotubes and graphene oxides induce autophagosome accumulation and lysosome impairment in primarily cultured murine peritoneal macrophages. Toxicol Lett. 2013;221(2):118-127.

140. Zhang W, Yan L, Li M, et al. Deciphering the underlying mechanisms of oxidation-state dependent cytotoxicity of graphene oxide on mammalian cells. Toxicol Lett. 2015;237(2):61-71.

141. Wilczek P, Major R, Lipinska L, Lackner J, Mzyk A. Thrombogenicity and biocompatibility studies of reduced graphene oxide modified acellular pulmonary valve tissue. Mater Sci Eng C Mater Biol Appl. 2015;53:310-321.

142. Pham VT, Truong VK, Quinn MD, et al. Graphene induces formation of pores that kill spherical and rod-shaped bacteria. ACS Nano. 2015;9(8):8458-8467.

143. Chang J, Mao S, Zhang Y, et al. Ultrasonic-assisted self-assembly of monolayer graphene oxide for rapid detection of Escherichia coli bacteria. Nanoscale. 2013;5(9):3620-3626.

144. Hernandez R, Valles C, Benito AM, Maser WK, Rius FX, Riu J. Graphene-based potentiometric biosensor for the immediate detection of living bacteria. Biosens Bioelectron. 2014;54:553-557.

145. Mannoor MS, Tao H, Clayton JD, et al. Graphene-based wireless bacteria detection on tooth enamel. Nat Commun. 2012;3:763.

146. Wan Y, Lin Z, Zhang D, Wang Y, Hou B. Impedimetric immunosensor doped with reduced graphene sheets fabricated by controllable electrodeposition for the non-labelled detection of bacteria. Biosens Bioelectron. 2011;26(5):1959-1964.

147. Chen Y, Michael ZP, Kotchey GP, Zhao Y, Star A. Electronic detection of bacteria using holey reduced graphene oxide. ACS Appl Mater Interfaces. 2014;6(6):3805-3810.

148. Akhavan O, Ghaderi E, Esfandiar A. Wrapping bacteria by graphene nanosheets for isolation from environment, reactivation by sonication, and inactivation by near-infrared irradiation. $J$ Phys Chem B. 2011;115(19):6279-6288.

149. Mejias Carpio IE, Santos CM, Wei X, Rodrigues DF. Toxicity of a polymer-graphene oxide composite against bacterial planktonic cells, biofilms, and mammalian cells. Nanoscale. 2012;4(15):4746-4756.

150. Nguyen TH, Lin M, Mustapha A. Toxicity of graphene oxide on intestinal bacteria and Caco-2 cells. J Food Prot. 2015;78(5):996-1002.

151. Nanda SS, An SS, Yi DK. Oxidative stress and antibacterial properties of a graphene oxide-cystamine nanohybrid. Int J Nanomedicine. 2015;10:549-556.

152. Kanchanapally R, Viraka Nellore BP, et al. Antimicrobial peptideconjugated graphene oxide membrane for efficient removal and effective killing of multiple drug resistant bacteria. RSC $A d v$ 2015;5(24):18881-18887.

153. Zhan S, Zhu D, Ma S, et al. Highly efficient removal of pathogenic bacteria with magnetic graphene composite. ACS Appl Mater Interfaces. 2015;7(7):4290-4298.

154. Wang YW, Cao A, Jiang Y, et al. Superior antibacterial activity of zinc oxide/graphene oxide composites originating from high zinc concentration localized around bacteria. ACS Appl Mater Interfaces. 2014;6(4):2791-2798.

155. Ahmed F, Rodrigues DF. Investigation of acute effects of graphene oxide on wastewater microbial community: a case study. J Hazard Mater. 2013;256-257:33-39.

156. Duan G, Kang SG, Tian X, et al. Protein corona mitigates the cytotoxicity of graphene oxide by reducing its physical interaction with cell membrane. Nanoscale. 2015;7(37):15214-15224.

157. Chong Y, Ge C, Yang Z, et al. Reduced cytotoxicity of graphene nanosheets mediated by blood-protein coating. ACS Nano. 2015;9(6):5713-5724.

158. Wu J, Yang R, Zhang L, Fan Z, Liu S. Cytotoxicity effect of graphene oxide on human MDA-MB-231 cells. Toxicol Mech Methods. 2015;25(4):312-319.

159. Ren H, Wang C, Zhang J, et al. DNA cleavage system of nanosized graphene oxide sheets and copper ions. ACS Nano. 2010;4(12):7169-7174.
160. Du L, Wu S, Li Y, Zhao X, Ju X, Wang Y. Cytotoxicity of PEGylated graphene oxide on lymphoma cells. Biomed Mater Eng. 2014;24(6):2135-2141.

161. Li Y, Feng L, Shi X, et al. Surface coating-dependent cytotoxicity and degradation of graphene derivatives: towards the design of non-toxic, degradable nano-graphene. Small. 2014;10(8):1544-1554.

162. Mullick CS, Lalwani G, Zhang K, Yang JY, Neville K, Sitharaman B. Cell specific cytotoxicity and uptake of graphene nanoribbons. Biomaterials. 2013;34(1):283-293.

163. Qiao Y, Zhang P, Wang C, Ma L, Su M. Reducing X-ray induced oxidative damages in fibroblasts with graphene oxide. Nanomaterials (Basel). 2014;4(2):522-534.

164. Qu G, Wang X, Wang Z, Liu S, Jiang G. Cytotoxicity of quantum dots and graphene oxide to erythroid cells and macrophages. Nanoscale Res Lett. 2013;8(1):198.

165. Lalwani G, Sundararaj JL, Schaefer K, Button T, Sitharaman B. Synthesis, characterization, phantom imaging, and cytotoxicity of a novel graphene-based multimodal magnetic resonance imaging - X-ray computed tomography contrast agent. J Mater Chem B Mater Biol Med. 2014;2(22):3519-3530.

166. Li J, Han Q, Wang X, et al. Reduced aggregation and cytotoxicity of amyloid peptides by graphene oxide/gold nanocomposites prepared by pulsed laser ablation in water. Small. 2014;10(21):4386-4394.

167. Waiwijit U, Kandhavivorn W, Oonkhanond B, et al. Cytotoxicity assessment of MDA-MB-231 breast cancer cells on screen-printed graphene-carbon paste substrate. Colloids Surf B Biointerfaces. 2014;113:190-197.

168. Wu S, Zhao X, Cui Z, et al. Cytotoxicity of graphene oxide and graphene oxide loaded with doxorubicin on human multiple myeloma cells. Int J Nanomedicine. 2014;9:1413-1421.

169. Ali-Boucetta H, Bitounis D, Raveendran-Nair R, Servant A, Van den Bossche J, Kostarelos K. Purified graphene oxide dispersions lack in vitro cytotoxicity and in vivo pathogenicity. Adv Healthc Mater. 2013;2(3):433-441.

170. Lammel T, Boisseaux P, Fernandez-Cruz ML, Navas JM. Internalization and cytotoxicity of graphene oxide and carboxyl graphene nanoplatelets in the human hepatocellular carcinoma cell line Hep G2. Part Fibre Toxicol. 2013;10:27.

171. Hu X, Ouyang S, Mu L, An J, Zhou Q. Effects of graphene oxide and oxidized carbon nanotubes on the cellular division, microstructure, uptake, oxidative stress, and metabolic profiles. Environ Sci Technol. 2015;49(18):10825-10833.

172. Cai X, Tan S, Yu A, et al. Sodium 1-naphthalenesulfonatefunctionalized reduced graphene oxide stabilizes silver nanoparticles with lower cytotoxicity and long-term antibacterial activity. Chem Asian J. 2012;7(7):1664-1670.

173. Liao KH, Lin YS, Macosko CW, Haynes CL. Cytotoxicity of graphene oxide and graphene in human erythrocytes and skin fibroblasts. $A C S$ Appl Mater Interfaces. 2011;3(7):2607-2615.

174. Wang A, Pu K, Dong B, et al. Role of surface charge and oxidative stress in cytotoxicity and genotoxicity of graphene oxide towards human lung fibroblast cells. J Appl Toxicol. 2013;33(10): 1156-1164.

175. Yuan J, Gao H, Sui J, Duan H, Chen WN, Ching CB. Cytotoxicity evaluation of oxidized single-walled carbon nanotubes and graphene oxide on human hepatoma HepG2 cells: an iTRAQ-coupled 2D LC-MS/MS proteome analysis. Toxicol Sci. 2012;126(1): 149-161.

176. Zhang H, Peng C, Yang J, et al. Uniform ultrasmall graphene oxide nanosheets with low cytotoxicity and high cellular uptake. ACS Appl Mater Interfaces. 2013;5(5):1761-1767.

177. Zhang M, Mao X, Wang C, et al. The effect of graphene oxide on conformation change, aggregation and cytotoxicity of HIV-1 regulatory protein (Vpr). Biomaterials. 2013;34(4):1383-1390.

178. Wu C, Wang C, Han T, Zhou X, Guo S, Zhang J. Insight into the cellular internalization and cytotoxicity of graphene quantum dots. Adv Healthc Mater. 2013;2(12):1613-1619. 
179. Yuan X, Liu Z, Guo Z, Ji Y, Jin M, Wang X. Cellular distribution and cytotoxicity of graphene quantum dots with different functional groups. Nanoscale Res Lett. 2014;9(1):108.

180. Zhang Y, Ali SF, Dervishi E, et al. Cytotoxicity effects of graphene and single-wall carbon nanotubes in neural phaeochromocytoma-derived PC12 cells. ACS Nano. 2010;4(6):3181-3186.

181. Ivask A, Voelcker NH, Seabrook SA, et al. DNA melting and genotoxicity induced by silver nanoparticles and graphene. Chem Res Toxicol. 2015;28(5):1023-1035.

182. De ML, Ottaviano L, Perrozzi F, et al. Flake size-dependent cyto and genotoxic evaluation of graphene oxide on in vitro A549, Caco-2 and vero cell lines. J Biol Regul Homeost Agents. 2014;28(2):281-289.

183. Na HK, Kim MH, Lee J, et al. Cytoprotective effects of graphene oxide for mammalian cells against internalization of exogenous materials. Nanoscale. 2013;5(4):1669-1677.

184. Chang H, Wang X, Shiu KK, et al. Layer-by-layer assembly of graphene, $\mathrm{Au}$ and poly(toluidine blue O) films sensor for evaluation of oxidative stress of tumor cells elicited by hydrogen peroxide. Biosens Bioelectron. 2013;41:789-794.

185. Tabei Y, Sonoda A, Nakajima Y, et al. Intracellular accumulation of indium ions released from nanoparticles induces oxidative stress, proinflammatory response and DNA damage. J Biochem. 2016;159(2):225-237.

186. Choi JS, Choi JY, Na HB, Seo TS. Quantitation of oxidative stress gene expression in human cell lines treated with water-dispersible $\mathrm{MnO}$ nanoparticles. J Nanosci Nanotechnol. 2015;15(6):4126-4135.

187. Bai W, Chen Y, Gao A. Cross talk between poly(ADP-ribose) polymerase 1 methylation and oxidative stress involved in the toxic effect of anatase titanium dioxide nanoparticles. Int $J$ Nanomedicine. 2015; 10:5561-5569.

188. Tee JK, Ong CN, Bay BH, Ho HK, Leong DT. Oxidative stress by inorganic nanoparticles. Wiley Interdiscip Rev Nanomed Nanobiotechnol. Epub 2015 Sep 10.
189. Mahitha B, Deva Prasad RB, Mallikarjuna K, Durga MC, Sushmal NJ. Bacopa monniera stabilized silver nanoparticles attenuates oxidative stress induced by aluminum in albino mice. J Nanosci Nanotechnol. 2015;15(2):1101-1109.

190. Nazarizadeh A, Asri-Rezaie S. Comparative study of antidiabetic activity and oxidative stress induced by zinc oxide nanoparticles and zinc sulfate in diabetic rats. AAPS PharmSciTech. Epub 2015 Sep 8.

191. Akhtar MJ, Alhadlaq HA, Alshamsan A, Majeed Khan MA, Ahamed M. Aluminum doping tunes band gap energy level as well as oxidative stress-mediated cytotoxicity of $\mathrm{ZnO}$ nanoparticles in MCF-7 cells. Sci Rep. 2015;5:13876.

192. Graham UM, Tseng MT, Jasinski JB, et al. In vivo processing of ceria nanoparticles inside liver: impact on free-radical scavenging activity and oxidative stress. Chempluschem. 2014;79(8):1083-1088.

193. Kalishwaralal K, Jeyabharathi S, Sundar K, Muthukumaran A. Sodium selenite/selenium nanoparticles (SeNPs) protect cardiomyoblasts and zebrafish embryos against ethanol induced oxidative stress. $J$ Trace Elem Med Biol. 2015;32:135-144.

194. Hashem RM, Rashd LA, Hashem KS, Soliman HM. Cerium oxide nanoparticles alleviate oxidative stress and decreases Nrf-2/HO-1 in D-GALN/LPS induced hepatotoxicity. Biomed Pharmacother. 2015;73:80-86.

195. Liu S, Zeng TH, Hofmann M, et al. Antibacterial activity of graphite, graphite oxide, graphene oxide, and reduced graphene oxide: membrane and oxidative stress. ACS Nano. 2011;5(9):6971-6980.

196. Gurunathan S, Han JW, Dayem AA, Eppakayala V, Kim JH. Oxidative stress-mediated antibacterial activity of graphene oxide and reduced graphene oxide in Pseudomonas aeruginosa. Int J Nanomedicine. 2012;7:5901-5914.
Nanotechnology, Science and Applications

\section{Publish your work in this journal}

Nanotechnology, Science and Applications is an international, peer-reviewed, open access journal that focuses on the science of nanotechnology in a wide range of industrial and academic applications. It is characterized by the rapid reporting across all sectors, including engineering, optics, bio-medicine, cosmetics, textiles, resource sustainability and science. Applied research into nano-materials,

\section{Dovepress}

particles, nano-structures and fabrication, diagnostics and analytics, drug delivery and toxicology constitute the primary direction of the journal. The manuscript management system is completely online and includes a very quick and fair peer-review system, which is all easy to use. Visit http://www.dovepress.com/ testimonials.php to read real quotes from published authors. 